\title{
Management of Pregnancy and Delivery in Patients With Hereditary Angioedema Due to C1 Inhibitor Deficiency
}

\author{
González-Quevedo $\mathrm{T}^{1,6,10, *}$, Larco $\mathrm{JI}^{2^{*}}$, Marcos $\mathrm{C}^{4,7,10}$, Guilarte $\mathrm{M}^{3,7,10}$, \\ Baeza $\mathrm{ML}^{5,8,10}$, Cimbollek $\mathrm{S}^{1,6,10}$, López-Serrano $\mathrm{MC}^{2,9,10}$, Piñero-Saavedra $\mathrm{M}^{1,10}$, \\ Rubio $\mathrm{M}^{5,8}$, Caballero $\mathrm{T}^{2,9,10}$
}

Both authors contributed equally to this study and to the manuscript 'Allergy Department, Hospital Universitario V del Rocío, Sevilla, Spain ${ }^{2}$ Allergy Department, Hospital Universitario La Paz, Madrid, Spain ${ }^{3}$ Allergy Department, Hospital Universitario Vall d'Hebron, Barcelona, Spain ${ }^{4}$ Allergy Department, Complexo Hospitalario Universitario de Vigo, Vigo, Spain ${ }^{5}$ Allergy Department, Hospital General Universitario Gregorio Marañon, Madrid, Spain ${ }^{6}$ Instituto de Biomedicina de Sevilla (IBIS), Sevilla, Spain

7Vall d'Hebrón Institut de Recerca (VHIR), Barcelona, Spain

${ }^{8}$ Institute for Health Research, Gregorio Marañon, (IIS-GM), Biomedical Research Network on Rare

Diseases-U761, Madrid, Spain

${ }^{9}$ Hospital La Paz Institute for Health Research (IdiPaz), Biomedical Research Network on Rare Diseases-U754, Barcelona, Spain

${ }^{10}$ Spanish Group for the Study of Bradykinin induced Angioedema (SGBA/GEAB)

J Investig Allergol Clin Immunol 2016; Vol. 26(3): 161-167

doi: 10.18176/jiaci.0037

\begin{abstract}
Background and Objective: There is little information on pregnancy and delivery in patients with hereditary angioedema due to C1 inhibitor deficiency (C1INH-HAE). The aim of this study was to describe the effect of pregnancy and deliveries on symptoms of C1INH-HAE and review the need for and safety of treatments available during the study period.

Methods: Retrospective review using a purpose-designed questionnaire of 61 C1INH-HAE patients from 5 hospitals specialized in the management of HAE in Spain. The outcomes measured were number of pregnancies, changes in symptoms during pregnancy and delivery, mode of delivery, type of anesthesia during delivery, treatments received, and tolerance of treatments.

Results: We reviewed 125 full-term pregnancies (89 without a prior diagnosis of C1INH-HAE), 14 miscarriages, and 4 induced abortions. Patients reported an increased frequency of C 1 INH-HAE symptoms in $59.2 \%$ of pregnancies $(74 / 125)$ and the presence of symptoms throughout pregnancy in 40\% (50/125). Prophylactic C1INH-HAE therapy was used during $9(7.2 \%)$ of the 125 pregnancies. Nine patients - in 11 pregnancies (8.8\%) -received treatment for acute attacks. Most deliveries $(n=110,88 \%)$ were vaginal. A cesarean section was necessary in 15 cases (12\%). Short-term prophylaxis with pdhC1INH was administered before 14 deliveries (11.2\%); 111 deliveries (88.8 \%) were performed without premedication and were well tolerated. Anesthesia was used in 51 deliveries (40.8\%). Conclusions: Pregnancy has a variable influence on the clinical expression of C1INH-HAE. Attacks tend to occur more frequently but not to increase in severity. Vaginal delivery was mostly well tolerated. pdhC1INH prophylaxis should be administered prior to cesarean delivery and is also recommended before vaginal delivery if there are additional risk factors. pdhC1INH should always be available in the delivery room. Key words: Hereditary angioedema. Pregnancy. Delivery. C1 inhibitor. Anesthesia. Treatment.
\end{abstract}

\section{Resumen}

Antecedentes y Objetivo: Existe escasa información sobre la evolución del embarazo y el parto en pacientes con angioedema hereditario con déficit de C1 Inhibidor (AEH-C1INH). El objetivo del estudio fue describir el efecto de embarazo y parto en los síntomas de AEH-C1INH y la necesidad y seguridad de las terapias disponibles durante dicho período. 
Diseño: Revisión retrospectiva de datos registrados en 5 centros hospitalarios españoles expertos en AEH.

Pacientes y Métodos: 61 mujeres con diagnóstico de AEH-C1INH antes o después de su(s) embarazo(s). Se rellenó un cuestionario específico. Fue evaluado: número de embarazos, evolución de síntomas de AEH durante embarazo(s) y parto(s), tipo de parto, tipo de anestesia durante el parto, tratamientos recibidos y su tolerancia.

Resultados: Se revisaron 125 embarazos a término (en 89 embarazos las pacientes estaban sin diagnosticar de AEH) y 18 abortos. Hubo aumento en la frecuencia de síntomas de AEH en 59,2\% de embarazos (74/125) y los síntomas estuvieron presentes a lo largo de todos los trimestres en el 40\% (50/125). Se usó tratamiento preventivo en 9 de los 125 embarazos (7,2\%). Nueve pacientes -en 11 embarazos$(8,8 \%)$ recibieron tratamiento para crisis agudas. 110 partos $(88 \%)$ fueron vaginales, mientras que $15(12 \%)$ fueron cesáreas. Se usó tratamiento profiláctico con concentrado de C1-Inhibidor (pdhC1INH) antes de 14 partos (11,2\%). Se completaron 111 partos $(88,8 \%)$ sin ningún tipo de premedicación y resultaron bien tolerados. Se usó anestesia en 51 partos $(41,6 \%)$.

Conclusiones: La influencia del embarazo en la expresión clínica de la enfermedad es variable, no obstante las crisis tienden a aumentar en frecuencia pero no en gravedad. El parto vaginal fue habitualmente bien tolerado. El pdhC1INH debe administrarse antes de un parto mediante cesárea y también se recomendaría en caso de parto vaginal si existiera algún factor de riesgo adicional. El pdhC1INH debe estar siempre disponible en la sala de partos.

Palabras clave: Angioedema hereditario. Embarazo. Parto. C1-Inhibidor. Anestesia. Tratamiento.

\section{Introduction}

Hereditary angioedema (HAE) due to $\mathrm{C} 1$ inhibitor deficiency (C1INH-HAE) is a rare disease [1]. In Spain, a minimal prevalence of 1.09 cases per 100000 inhabitants has been reported [2]. Two subtypes of C1INH-HAE have been described: type I C1INH-HAE with reduced yet functional $\mathrm{C} 1$ inhibitor levels and type II C1INH-HAE, with normal or high C1INH protein levels but reduced C1INH function [3]. Another type of HAE with normal C1INH levels has also been described [4,5], but in this paper we focus just on types I and II.

C1INH-HAE is characterized by nonpruritic, nonpitting edema that typically affects different locations. Abdominal pain, distension, nausea, or vomiting may also be present secondary to edema of submucosal tissues of the gastrointestinal tract [6]. Upper airway involvement can be fatal, and mortality due to suffocation can be as high as $33 \%$ in inappropriately treated patients [7]. Estrogens, trauma, and stressful situations can worsen the course of disease and consequently, pregnancy and delivery may be special periods for female patients [8-10].

Three treatment options are available for C1INH-HAE: long-term prophylaxis (LTP), short-term prophylaxis (STP), and acute treatment. LTP consists mainly of attenuated androgens (AAs), but these can cross the placental barrier, possibly producing virilization, and should therefore be strictly avoided during pregnancy and lactation; antifibrinolytic agents are also used for LTP, though they are less effective $[11,12]$. Plasma-derived human $\mathrm{C} 1$ inhibitor ( $\mathrm{pdhC} 1 \mathrm{INH}$ ) can be used for LTP when other treatments are contraindicated, ineffective, or poorly tolerated. STP with pdhC1INH is the most effective preventive therapy for patients undergoing surgery. pdhC1INH has traditionally been the treatment of choice for acute attacks during pregnancies; an alternative, though less safe, option is fresh frozen plasma $[13,14]$. Icatibant acetate, a B2 receptor blocker, as well as a recombinant version of the human $\mathrm{C} 1$ inhibitor protein, have been approved by the European Medicines Agency and the US Food and Drug Administration, and together with ecallantide, are licensed for the treatment of acute edema attacks in adult patients; they have not yet, however, been approved for use in pregnancy [15-17]. In this study, we describe the experience of 5 major HAE centers in Spain in managing C1INH-HAE during pregnancy and delivery with the aim of adding to the body of knowledge regarding the management of obstetric events in this setting.

\section{Patients and Methods}

Patients from 5 HAE reference hospitals in Spain were recruited for the study. The participating centers were Hospital Universitario Virgen del Rocío in Sevilla, Andalusia, Hospital Universitario La Paz in Madrid, Complejo Hospitalario Universitario de Vigo in Vigo, Galicia, Hospital Universitario Vall d'Hebron in Barcelona, Catalonia, and Hospital General Universitario Gregorio Marañón in Madrid. We performed a retrospective study of C1INH-HAE patients who had become pregnant before or after C1INH-HAE diagnosis. A specific questionnaire was designed and filled out with information from clinical charts or from telephone interviews when data were missing. Information about full-term pregnancies, miscarriages, and induced abortions was also included. The research ethics committees of Hospital Universitario Virgen del Rocío and Hospital Universitario La Paz approved the study.

The criteria to define worsening of symptoms compared with the baseline condition included an increase in attack frequency as well as the duration of single attacks. Increased severity was also considered a criterion of worsening but there were no cases (ie, there were no changes in the distribution of sites of involvement). The criteria to define an improvement in HAE symptoms included no symptoms, fewer symptoms, or milder attacks.

Descriptive statistics were used to summarize and analyze the collected data. Analysis was performed using the IBM SPSS v19.0 statistical package. Quantitative variables were described as means and ranges; qualitative variables were recorded as absolute values and percentages. Categorical variables were compared using the $\chi^{2}$ Pearson test. $P$ values of less than .05 was considered to be statistically significant. 


\section{Results}

We reviewed 125 pregnancies in 61 patients as well as 14 miscarriages and 4 induced abortions. The percent distribution of patients and full-term pregnancies among the 5 study hospitals are shown in the Figure.

The mean age of patients at the time of C1INH-HAE diagnosis was 30.6 years (range, 6-60 years), and the mean age at the start of pregnancy was 27.1 years (range, 16-42 years). There was a prior diagnosis of C1INH-HAE in just $44(30.7 \%)$ of the 143 initial gestations and in $36(28.8 \%)$ of the 125 fullterm pregnancies. Thirty-five women $(57.4 \%)$ were not aware that they had HAE during 89 pregnancies $(71.2 \%)$. Twenty of the 61 patients had only 1 pregnancy. Data were collected between the years 2006 and 2010 and corresponded to pregnancies that had occurred more than 20 years previously in nearly half of the patients $(49.2 \%), 6$ of whom had only been pregnant once.

Only 13 patients $(21.3 \%)$ were receiving LTP before they became pregnant. Nine patients had been receiving AAs. Seven of these stopped AA therapy before they conceived and the other 2 stopped 1 month after conception, on confirmation of their pregnancy.

A greater frequency or duration of acute attacks was reported for $59.2 \%$ of the pregnancies, no changes with
Patients $(n=61)$

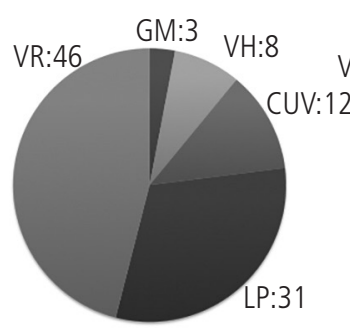

Full-term pregnancies $(n=125)$

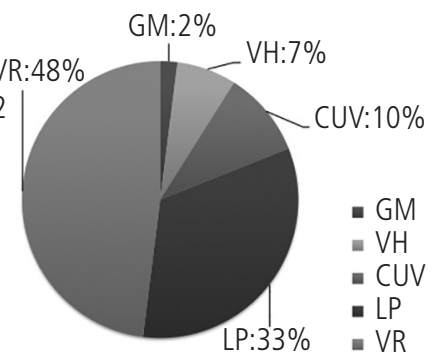

Figure 1. Distribution of patients and full-term pregnancies among the 5 reference hospitals for hereditary angioedema. CUV indicates Complejo Hospitalario Universitario de Vigo; GM, Hospital General Universitario Gregorio Marañón; LP, Hospital Universitario La Paz; VH, Hospital Universitario Vall d'Hebron; VR, Hospital Universitario Virgen del Rocío.

Table 1. Changes in C1INH-HAE Symptoms During Pregnancy in Patients With and Without a Previous Diagnosis of C1INH-HAE ${ }^{\mathrm{a}}$

\begin{tabular}{l|c|c|c}
\hline \multicolumn{2}{|c|}{} & \multicolumn{2}{c}{$\begin{array}{c}\text { Previous diagnosis } \\
\text { of C1INH-HAE }\end{array}$} \\
\cline { 3 - 4 } & $\begin{array}{c}\text { Yes } \\
\mathrm{n}=36(28.8 \%)\end{array}$ & $\begin{array}{c}\text { No } \\
\mathrm{n}=89(71.2 \%)\end{array}$ \\
\hline $\begin{array}{l}\text { Worsening of } \\
\begin{array}{l}\text { C1INH-HAE } \\
\text { symptoms } \\
\text { during } \\
\text { pregnancy (\%) }\end{array}\end{array}$ & No 51 (40.8) & $12(33.3)$ & $39(43.8)$ \\
\cline { 2 - 4 } & Yes 74 (59.2) & $24(66.7)$ & $50(56.2)$ \\
\hline
\end{tabular}

Abbreviation: C1INH-HAE, hereditary angioedema due to C1 inhibitor deficiency.

${ }^{a}$ No statistically significant differences were noted between groups. respect to baseline symptoms were reported in $26.4 \%$ of cases, and symptoms improved in $14 \%$ of cases. There were no differences in attack severity from one trimester to the next, and in $40.0 \%(50 / 125)$ of pregnancies HAE symptoms were present throughout the pregnancy. Patients with more than 1 gestation $(67.2 \%)$ generally described a similar course for each of their pregnancies (similar C1INH-HAE symptoms in $85.4 \%$ of cases). There were no changes in sites of involvement but there was an increase in the frequency of mild abdominal crises. Non-life-threatening symptoms were reported in the 125 full-term pregnancies or abortions.

We found no statistically significant differences for disease course on comparing percentages between the group of women with a known C1INH-HAE diagnosis before pregnancy $(n=36)$ and the group of women with an unknown C1INH-HAE diagnosis at the time of pregnancy $(n=89)$ (Table 1).

LTP was only used during 9 of the 125 pregnancies: epsilon-amino-caproic acid was used in 1 case, tranexamic acid in 2 cases, AAs in 2 cases, and pdhC1INH (Berinert, CSL-Behring) in 4 cases. In the 2 cases in which AAs were temporarily used (for 8 and 12 weeks), the drug was administered after confirmation that the fetus was male. (As mentioned previously, 2 other patients interrupted LTP with AAs when they became aware they were pregnant.)

Our patients reported 14 miscarriages, most of which occurred during the first trimester. Additionally, there were 4 registered abortions. There were also 3 fetal deaths and 1 premature delivery with complications (deafness and visual problems). None of the miscarriages or cases of fetal damage occurred in patients temporarily exposed to AAs.

Nine patients received treatment for an acute attack during 11 pregnancies. pdhC1INH (Berinert) was administered in all 9 cases and 1 of the patients additionally received tranexamic acid and other corticosteroids. This last patient was not diagnosed with C1INH-HAE until 5 years later.

Seven patients were administered a total of 618 vials of pdhC1INH $500 \mathrm{U}$ (Berinert) to treat acute attacks and as LTP ( 4 cases) in 9 pregnancies (average of 4.16 vials $/ \mathrm{mo}$ ); 1 patient received, as LTP, a total of 356 vials in 2 consecutive pregnancies (average 4.94 vials/wk); no adverse effects were reported.

None of the newborns developed health problems or experienced adverse effects attributable to any of the drugs used.

The vast majority of deliveries ( $\mathrm{n}=110,88 \%)$ were vaginal; forceps and vacuum extraction were used in 9 and 5 deliveries, respectively (Table 2). Cesarean sections were necessary in 15

Table 2. Mode of Delivery and Type of Anesthesia

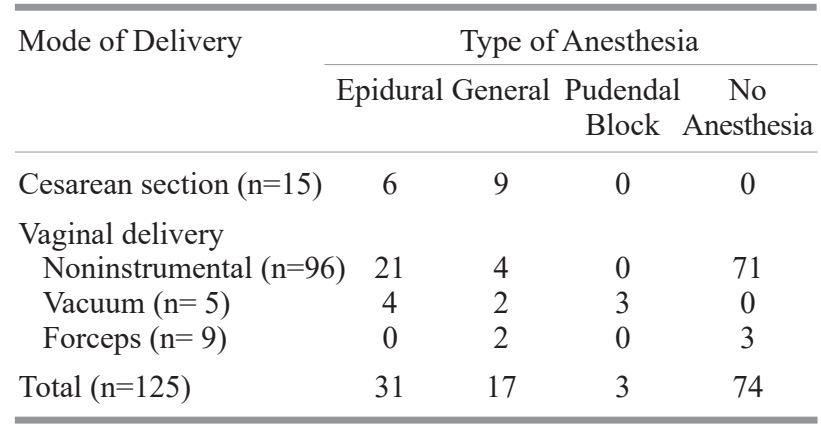


Table 3. Reasons for Cesarean Delivery (Rate 12\%)

\begin{tabular}{llllll}
\hline Patient & Year & $\begin{array}{c}\text { Pregnancy } \\
\text { Number }\end{array}$ & Age, y & Type & Reasons \\
\hline 1 & 1975 & Second & 28 & Acute & Dystocia \\
2 & 1983 & First & 19 & Elective & Narrow pelvic opening \\
3 & 1983 & First & 23 & Acute & Anomalies of umbilical cord \\
4 & 1984 & Third & 39 & Elective & Other complications \\
5 & 1985 & Third & 25 & Acute & Dystocia \\
6 & 1993 & Second & 40 & Elective & Other complications \\
7 & 1994 & First & 29 & Acute & Dystocia \\
8 & 1994 & Second & 27 & Elective & HAE diagnosed during pregnancy \\
9 & 1996 & First & 27 & Elective & Narrow pelvic opening \\
10 & 1998 & First & 28 & Elective & Unknown. Known diagnosis of HAE \\
11 & 2001 & Second & 37 & Elective & Narrow pelvic opening \\
12 & 2002 & First & 27 & Acute & Fetal bradycardia. Known diagnosis of HAE \\
13 & 2005 & First & 36 & Elective & Unknown. Known diagnosis of HAE \\
14 & 2006 & Second & 35 & Elective & Fetus in breech position. Known diagnosis of HAE \\
15 & 2007 & Third & 28 & Acute & Dystocia \\
& & & &
\end{tabular}

Abbreviation: HAE, hereditary angioedema.

deliveries (the reasons are summarized in Table 3). Only 5 of the 15 women who underwent a cesarean section knew that they had C1INH-HAE and had been treated with pdhC1INH prior to delivery; tolerance was good in all cases and the 10 women who did not receive premedication for the cesarean section did not recall any adverse perioperative events.

Anesthesia was used in 51 deliveries (40.8\%) and in the 4 induced abortions. No specific complications associated with the anesthesia were reported.

STP with pdhC1INH was only administered prior to 14 deliveries; 5 patients received $1000 \mathrm{U}$ and 9 patients received $500 \mathrm{U}$. All the patients demonstrated good tolerance of the infusion and no adverse events were reported. Of the 14 patients who received STP before delivery, 8 had experienced a worsening of C1INH-HAE symptoms during pregnancy and 4 reported no changes with respect to before the pregnancy. None of these 14 patients had HAE symptoms during delivery or in the next 48 hours. No premedication was used in 111 deliveries and mild local C1INH-HAE symptoms were observed in just 6 vaginal deliveries $(5.4 \%)$. These local symptoms ceased spontaneously.

\section{Discussion}

We have reported on the course and management of 125 full-term pregnancies and deliveries, 14 miscarriages, and 4 induced abortions in $61 \mathrm{C} 1 \mathrm{INH}-\mathrm{HAE}$ patients through a nationwide cooperation study. A clear set of international C1INH-HAE guidelines containing recommendations for delivery and pregnancy follow-up and information on the benefits and risks associated with each of the available treatments was published only recently $[12,13]$. Three case series have been published [18-20], but most publications on
HAE and pregnancy report on few pregnancies and deliveries (between 1 and 3). Our study is the largest to date and can be considered representative of the approach to and management of pregnancies and deliveries in C1INH-HAE patients in Spain in recent decades.

Mild aggravation of C1INH-HAE symptoms was experienced in $59.2 \%$ of the pregnancies in our series; this figure is similar to previous reports $[18,19]$. The mild worsening detected is more likely to be attributable to changes associated with pregnancy rather than to discontinuation of HAE treatment, as most patients were not receiving regular treatment before they became pregnant.

No statistically significant differences were observed for course of disease on comparing patients with a previous diagnosis of C1INH-HAE and those without one (Table 1). Of the 36 pregnancies in which there was a confirmed diagnosis of HAE before pregnancy, there was an improvement in clinical signs in 6 cases $(16.7 \%)$ and no changes in another 6 .

The majority of the 41 patients with more than 1 pregnancy (85.4\%) noted that the disease manifested itself in a similar way during each pregnancy and only 4 patients described a change in symptoms from one pregnancy to the next.

The course of symptoms has been reported to vary greatly between pregnancy trimesters $[18,19]$, but in more than half of the pregnancies in our series, there were reports of worsening of symptoms throughout the pregnancies, with no clear differences observed between trimesters.

Chinniah and Katelaris [20] described a group of 7 patients with 16 pregnancies who experienced fewer attacks as the pregnancy progressed and more attacks during the first trimester. In all cases, the patients had edema attacks, but the authors did not report whether symptoms worsened during pregnancy in comparison with previous or posterior periods. 
In our case series, none of the 14 miscarriages were directly related to angioedema attacks and this rate of $10.1 \%$ can be considered low compared with average rates reported for the general European population (10\%-20\%) [10]. The decision to terminate the pregnancy was at least partially related to the diagnosis of HAE in 2 of the 4 voluntary interruptions. One of the 3 fetal deaths was due to a congenital cardiopathy and 2 (in the same woman) were due to $\mathrm{Rh}$ incompatibility. There was just 1 newborn who developed complications because of premature delivery (at 6 months). None of these cases were related to the temporary use of androgens.

Almost all studies of patients with C1INH-HAE have reported good progression of HAE symptoms during pregnancy and delivery. Although HAE symptoms may be present, they are usually mild and rarely life-threatening. Mc Glinchey et al [21] reported a life-threatening laryngeal angioedema attack in the 25 th week of gestation that was treated with fresh frozen plasma and $2000 \mathrm{U}$ of pdhC1INH and resolved completely. Postnikoff and Pritzker [22] wrote about the only death reported of a pregnant HAE woman 110 hours after delivery. This patient developed perineal swelling and a purulent discharge from the episiotomy 48 hours postpartum. Autopsy revealed edema of the subcutaneous tissues, which was most prominent in the perineal region, with severe effusions present within all body cavities and septic shock.

LTP during pregnancy was seldom used in the pregnancies reported in this case series; in some cases the patients had not yet been diagnosed with C1INH-HAE, while in others presumably little was known at the time about the safety of C1INH-HAE treatments. We administered C1INH concentrate as LTP in 4 pregnancies in 2009 and 2010; the drug was administered off-label, with the patients' informed consent, due to a clear exacerbation of symptoms following discontinuation of effective AA therapy.

In our series vaginal delivery without prophylactic treatment was well tolerated, and although trauma and stress are known to trigger attacks, very few patients developed mild local edema. There have been many isolated reports of pregnant C1INH-HAE patients who experienced no edema attacks after a vaginal or cesarean delivery with prophylactic pdhC1INH treatment [23-28]. There have also been reports of 2 cesarean deliveries [29] and 2 vaginal deliveries [30] that were well tolerated without prophylactic therapy. Anecdotal reports of STP with fresh frozen plasma and danazol prior to delivery, with good outcomes, have also been published $[31,32]$. In the series reported by Martinez-Saguer et al [19], all the patients received prophylactic pdhC1INH treatment prior to delivery. Chinniah and Katelaris [20] did not report any symptomatic deliveries in their case series, although prophylactic pdhC1INH was used in only 5 of the 16 deliveries. In the series by Czaller et al [18], prophylactic treatment prior to delivery was used in 9 of 82 deliveries, with good tolerance in all cases; the same authors described asymptomatic deliveries in the 73 deliveries performed without prophylaxis. The proportion of deliveries without pretreatment and the good outcomes in cases in which prophylaxis was not used match the findings of our case series.

Only 5 of 15 women who underwent a cesarean section in our series knew about their condition and were treated with pdhC1INH prior to delivery. Of the 10 cesarean deliveries that did not include prophylactic treatment, a single patient experienced mild HAE symptoms during delivery and 48 hours postpartum and subsequently required treatment with pdhC1INH. Czaller et al [18] described the use of prophylactic treatment prior to cesarean delivery in 1 of 8 cases and reported no symptoms in any of these deliveries. Martinez-Saguer et al [19], in turn, reported 8 cesarean sections out of 35 deliveries; in all cases, the patients underwent prophylactic treatment with pdhC1INH immediately before delivery and no attacks were reported.

Our study has certain limitations. Information was obtained retrospectively through a questionnaire completed using clinical records and telephone interviews in the case of missing data. Due to the retrospective nature of the study, the information corresponded to pregnancies from several years earlier (up to 20 years in nearly half of the patients). It is also important to note that C1INH-HAE had not been previously diagnosed in 89 pregnancies, and in the majority of cases, a diagnosis was not made until several years later. Therefore, the patients may have underestimated the severity of symptoms or failed to associate them with C1INH-HAE. Nevertheless, the fact that most patients had not been diagnosed with $\mathrm{C} 1 \mathrm{INH}-$ HAE before conception and did not receive any treatment during pregnancy provides interesting insights into the natural course of C1INH-HAE during pregnancy and labor.

In conclusion, after reviewing data from our series we can conclude that pregnancy appears to have a variable influence on the clinical expression of C1INH-HAE, and may differ from one patient to another and to a lesser extent, from one pregnancy to the next. Attacks tend to occur more frequently but they do not appear to increase in severity. pdhC1INH prophylaxis should be administered prior to cesarean delivery and is also highly recommended for vaginal delivery in patients with additional risks factors or severe C1INH-HAE symptoms during pregnancy or previous deliveries. pdhC1INH (2000 U) should always be available in the delivery room and during hospitalization. To improve outcomes in pregnant women with C1INH-HAE, it would be wise to maintain observation for 48 hours postpartum.

\section{Acknowledgments}

The authors would like to thank SEAIC (Sociedad Española de Alergología e Inmunología Clínica) for the support provided to GEAB-SGBA (Spanish Group for the Study of Bradykinin induced Angioedema) and to Juan Manuel Praena (FISEVI researcher and statistician, HUVRocio) for his statistical support. They are also immensely grateful to Erin Lillian Roblin for her comments and English corrections on an earlier version.

\section{Conflicts of Interest}

Dr Caballero has received sponsorship for educational purposes, has been paid for providing consultancy services, and has taken part in clinical trials sponsored by Jerini AG/Shire, CSL-Behring, Dyax Corp, Pharming NV, and Viropharma Pharmaceutical.

Dr Cimbollek has received sponsorship for educational purposes and has taken part in clinical trials sponsored by CSL-Behring, and Pharming NV. 
Dr González-Quevedo has received speaker's fees from Jerini AG/Shire, has been paid for providing consultancy services to Viropharma Pharmaceutical, and has received sponsorship for educational purposes and taken part in clinical trials sponsored by CSL-Behring, Dyax Corp, and Pharming NV.

Dr Guilarte has received sponsorship for educational purposes, has been paid for providing consultancy services to Jerini AG/Shire, and has participated in clinical trials sponsored by Jerini AG/Shire and Pharming NV.

Dr. Ignacio Larco has taken part in a clinical trial sponsored by CSL-Behring.

Dr López-Serrano has received sponsorship for educational purposes, been paid for providing consultancy services, and taken part in clinical trials sponsored by Jerini AG/Shire, CSLBehring, Dyax Corp, and Pharming NV.

Dr Marcos has been paid for providing consultancy services and received speaker's fees and sponsorship for educational purposes from Jerini AG/Shire.

\section{References}

1. Mansi M, Zanichelli A, Coerezza A, Sufffritti C, Wu MA, Vacchini R, Stieber C, Cichon S, Cicardi M. Presentation, diagnosis and treatment of angioedema without wheals: a retrospective analysis of a cohort of 1058 patients. J Int Med 2015; 277(5) 585-93.

2. Roche O, Blanch A, Caballero MT, Sastre N, Callejo D, Lopez Trascasa M. Hereditary angioedema due to C1 Inhibitor deficency: patient registry and approach to the prevalence in Spain. Ann Allergy Asthma Immunol 2005;94(4):498-503.

3. Rosen FS, Pensky J, Donaldson V, Charache P. Hereditary Angioneurotic edema: two genetic variants. Science. 1965;148(3672):957-8.

4. Bork K, Barnstedt SE, Koch P, Traupe H. Hereditary angioedema with normal C1-inhibitor activity in women. Lancet. 2000;356(9225):213-7.

5. BinKley $K E$, Davis A 3rd. Clinical, biochemical and genetic characterization of a novel estrogen-dependent inherited form of angioedema. J Allergy Clin Immunol. 2000;106(3):546-50.

6. Agostoni A, Aygören-Pürsün $E$, Binkley KE, Blanch $A$, Bork K, Bouillet L, Bucher C, Castaldo AJ, Cicardi M, Davis AE, De Carolis C, Drouet C, Duponchel C, Farkas H, Fáy K, Fekete B, Fischer B, Fontana L, Füst G, Giacomelli R, Gröner A, Hack CE, Harmat G, Jakenfelds J, Juers M, Kalmár L, Kaposi PN, Karádi I, Kitzinger A, Kollár T, Kreuz W, Lakatos P, Longhurst HJ, LopezTrascasa M, Martinez-Saguer I, Monnier N, Nagy I, Németh E, Nielsen EW, Nuijens JH, O'Grady C, Pappalardo E, Penna V, Perricone C, Perricone R, Rauch U, Roche O, Rusicke E, Späth PJ, Szendei G, Takács E, Tordai A, Truedsson L,Varga L, Visy B, Williams K, Zanichelli A, Zingale L. Hereditary and acquired angioedema: problems and progress: proceedings of the third C1 esterase inhibitor deficiency workshop and beyond. J Allergy Clin Immunol. 2004;114 (3 Suppl):S51-131.

7. Bork K, Hardt J, Witzke G. Fatal laryngeal attacks and mortality in HAE due to C1INH deficiency. J Allergy Clin Immunol 2012;130(3):692-7

8. Bowen T, Cicardi M, Farkas H, Bork K, Longhurst HJ, Zuraw $B$, Aygoeren-Pürsün E, Craig T, Binkley K, Hebert J, Ritchie $B$,
Bouillet L, Betschel S, Cogar D, Dean J, Devaraj R, Hamed A, Kamra P, Keith PK, Lacuesta G, Leith E, Lyons H, Mace S, Mako $B$, Neurath D, Poon MC, Rivard GE, Schellenberg R, Rowan $D$, Rowe $A$, Stark $D$, Sur $S$, Tsai $E$, Warrington $R$, Waserman S, Ameratunga R, Bernstein J, Björkander J, Brosz K, Brosz J, Bygum A, Caballero T, Frank M, Fust G, Harmat G, Kanani A, Kreuz W, Levi M, Li H, Martinez-Saguer I, Moldovan D, Nagy I, Nielsen EW, Nordenfelt P, Reshef A, Rusicke E, Smith-Foltz S, Späth P, Varga L, Xiang ZY. 2010 international consensus algorithm for the diagnosis, therapy and management of hereditary angioedema. Allergy Asthma Clin Immunol 2010;6(1):24.e1-13.

9. Longhurst HJ. Emergency treatment of acute attacks in hereditary angioedema due to $\mathrm{C} 1$ inhibitor deficiency: what is the evidence? Int J Clin Pract 2005;59(5):594-9.

10. Bouillet L, Longhurst $H$, Boccon-Gibod I, Bork K, Bucher C, Bygum A, Caballero T, Drouet C, Farkas H, Massot C, Nielsen EW, Ponard D, Cicardi M. Disease expression in women with hereditary angioedema. Am J Obstet Gynecol. 2008;199(5):484.e1-4

11. Caballero T, Canabal J, Rivero-Paparoni D, Cabañas R. Management of hereditary angioedema in pregnant women: a review. Int J Womens Health. 2014;6:839-48.

12. Caballero T, Farkas $H$, Bouillet $L$, Bowen $T$, Gompel $A$, Fagerberg C, Bjökander J, Bork K, Bygum A, Cicardi M, de Carolis C, Frank M, Gooi JH, Longhurst H, Martínez-Saguer I, Nielsen EW, Obtulowitz K, Perricone R, Prior N. C-1-INH Deficiency Working Group. International consensus and practical guidelines on the gynecologic and obstetric management of female patients with hereditary angioedema caused by $\mathrm{C} 1$ inhibitor deficiency. J Allergy Clin Immunol. 2012;129(2):308-20.

13. Craig T, Aygoren-Pursun E, Bork K, Bowen T, Boysen H, Farkas $\mathrm{H}$, Grumach A, Katelaris CH, Lockey R, Longhurst H, Lumry W, Magerl M, Martinez-Saguer I, Ritchie B, Nast A, Pawankar R, Zuraw B, Maurer M. WAO Guideline for the Management of Hereditary Angioedema. WAO Journal. 2012;5(12):182-99.

14. De Serres J, Gröner A, Lindner J. Safety and efficacy of pasteurized $\mathrm{C} 1$ inhibitor concentrate (Berinert $\mathrm{P}$ ) in hereditary angioedema: a review. Transfus Apher Sci. 2003;29(3):24754.

15. Gras J. Icatibant for Hereditary Angioedema. Drugs Today. 2009;45(12):855-64.

16. Zuraw B, Cicardi $M$, Levy RJ, Nuijens JH, Relan A, Visscher S, Haase G, Kaufman L, Hack CE . Recombinant human C1 -Inhibitor for the treatment of acute angioedema attcks in patients with hereditary angioedema. J Allergy Clin Immunol. 2010;126(4):821-7.

17. Levy RJ, Lumry WR, McNeil DL, Li HH, Campion M, Horn PT, Pullman WE. Edema 4: a phase 3, double blind study of subcutaneous ecallantide treatment for acute attacks of hereditary Angioedema. Ann Allergy Asthma Immunol. 2010;104(6):523-9.

18. Czaller I, Visy B, Csuka D, Füst G, Tóth F, Farkas H. The natural history of hereditary angioedema and the impact of treatment with human C1-inhibitor concentrate during pregnancy: a long-term survey. Eur J Obstet Gynecol Reprod Biol. 2010;152(1):44-9.

19. Martinez-Saguer I, Rusicke $E$, Aygören-Pürsün $E$, Heller $C$, Klingebiel T, Kreuz W. Characterization of acute hereditary 
angioedema attacks during pregnancy and breast-feeding and their treatment with $\mathrm{C} 1$ inhibitor concentrate. Am J Obstet Gynecol. 2010;203(2):131.e1-7.

20. Chinniah N, Katelaris $\mathrm{CH}$. Hereditary angioedema and pregnancy. Austr N Z J Obstet Gynaecol. 2009;49(1):2-5.

21. McGlinchey PG, Golchin K, McCluskey DR. Life-threatening laryngeal oedema in a pregnant woman with hereditary angioedema. Ulster Med J. 2000;69:54-7.

22. Postnikoff IM, Pritzker KPH. Hereditary angioneurotic edema: an unusual case of maternal mortality. J Forensic Sci. 1979;24(2):473-8.

23. Montinaro V, Castellano G. Managment of pregnancy and vaginal delivery by $\mathrm{C} 1$ inhibitor concentrate in two hereditary angioedema twins. Clin Immunol. 2010;136(3):456-7.

24. Nathani F, Sullivan $H$, Churchill D. Pregnancy and C1 esterase inhibitor deficiency: a successful outcome. Arch Gynecol Obstet. 2006;274(6):381-4.

25. Marescal C, Ducloy-Bouthors AS, Laurent J, Vankemmel F, Gaucher A, Dufour P, Krivosic-Horber R. Parturition and angioneurotic oedema. Int J Obstet Anesth. 1999;8(2):135-7.

26. Caliskaner Z, Ozturk S, Gulec M, Dede M, Erel F, Karaayvaz M. A successful pregnancy and uncomplicated labor with C1INH concentrate prophylaxis in a patient with hereditary angioedema. Allergol Immunopathol. 2007;35(3):117-9.

27. Hawthorne LA, Gooi HC. Hereditary angioedema: prophylaxis management in the puerperium. Anaesthesia. 1996:51(3):283-4.

28. Cox M, Holdcroft A. Hereditary angioneurotic oedema: current management in pregnancy. Anaesthesia. 1995;50(6):547-9.
29. Chappatte O, De Swiet M. Hereditary angioneurotic oedema and pregnancy. Case reports and review of the literature. $\mathrm{Br} J$ Obstet Gynaecol. 1988;95(9):938-42.

30. Stiller RJ, Kaplan BM, Andreoli JW. Hereditary angioedema and pregnancy. Obstet Gynecol. 1984;64(1):133-5.

31. Galan HL, Reedy MB, Starr J, Knight AB. Fresh frozen plasma prophylaxis for hereditary angioedema during pregnancy. A case report. J Reprod Med. 1996;41(7):541-4.

32. Boulos AN, Brown R, Hukin A, Williams RM. Danazol prophylaxis for delivery in hereditary angioneurotic oedema. Br J Obstet Gynaecol. 1994;101(12):1094-5.

Manuscript received November 23, 2014; accepted for publication, August 3, 2015.

\section{- Teresa González-Quevedo}

Servicio de Alergia, Unidad de Referencia de Angioedema para Andalucia Hospital Universitario V del Rocío Edificio Centro de Diagnóstico Av Manuel Siurot s/n, 41013 Sevilla, Spain E-mail: mtgonzalezq@gmail.com 